\title{
The Use of High Sensitivity C-Reactive Protein in Cardiovascular Disease Detection
}

\author{
Ana Rita Castro ${ }^{1}$; Sara Oliveira Silva ${ }^{2}$, Sandra Clara Soares ${ }^{1}$ \\ ${ }^{1}$ Fernando Pessoa Energy, Environment and Health Research Unit/Biomedical Research Center (FP-ENAS/CEBIMED), \\ Faculty of Health Sciences, Fernando Pessoa University, Porto, Portugal; ${ }^{2}$ SIER Group, Vila do Conde, Portugal.
}

Received, October 25, 2018; Revised, November 11, 2018; Accepted, November 24, 2018; Published, November $26,2018$.

\begin{abstract}
Cardiovascular diseases (CVDs) are responsible for a high mortality rate worldwide. One of the most common causes of CVDs is vascular inflammation associated to atherosclerosis. Inflammatory biomarkers are used to assist the detection of CVDs and monitor their evaluation, prognosis and therapy implementation. C-reactive protein (CRP) is an acute phase protein produced after stimulation by proinflammatory cytokines. CRP is a biomarker of the inflammatory reaction and an important mediator of atherosclerosis. Given it actively contributes to the development of the atherosclerotic plaque, instability and subsequent clot formation it is also considered a CVD risk factor. Since 2010, the plasma concentration of hsCRP (high sensitivity CRP) has been used as a biomarker for disease prognosis in patients with intermediate risk for CVDs. It could be useful to establish a high concentration limit of hsCRP that can be used by clinicians for diagnosis of acute myocardial infarction, cardio embolic or ischemic stroke, and hypertrophic cardiomyopathy. The end cost/effectiveness of hsCRP screening is still an area of controversy but it is a priority to make the medical community aware of the positive relation between high hsCRP and CVDs to improve median survival and life quality of the patients.
\end{abstract}

\section{INTRODUCTION}

Cardiovascular diseases (CVDs) are the main cause for death and premature incapacity worldwide (1) and in Portugal (2), despite the considerable reduction of the morbidity and mortality rates observed in the last decades. The high prevalence of CVD risk factors drives a continuous clinical surveillance concerning the prevention, rapid diagnosis, and appropriate treatment (1).

CVDs are inflammatory conditions (3), associated with increased expression of proinflammatory mediators (4). Elevated proinflammatory mediators following CVD, such as myocardial infarction, are associated to mortality (5). Among several inflammatory biomarkers, such as interleukins (IL) 1 and 6 and tumour necrosis factor- $\alpha$ (TNF- $\alpha)$, C-reactive protein (CRP) emerges as an acute phase protein that is overexpressed in/during CVDs (6). It is produced by several cell types, including hepatocytes and monocytes, in response to CVDs as well as other inflammatory conditions such as arthritis, infection, cancer, and mental diseases $(7,8)$. Increased levels of high sensitivity CRP (hsCRP) may be used as a tool to facilitate diagnosis, prevention and treatment of CVDs. Thus, hsCRP is considered by several authors, an excellence marker of inflammation $(9,10)$.
CRP also plays a role in the pathogenesis of atherosclerosis contributing to lesion development, plaque rupture and having a proatherogenic effect. Atherosclerosis is the most frequent cause of CVD besides infections. It contributes to the high mortality rate following a cardiovascular event. Thus, hsCRP should be considered in association with cardiac biomarkers in the early diagnosis and therapeutic monitoring of CVD (11).

\section{ATHEROSCLEROSIS INFLAMMATORY PROCESS AND INFLAMMATORY BIOMARKERS}

Atherosclerosis is an inflammatory chronic disease of multifactorial aetiology, slow and progressive, and is considered the most important cause of death and premature incapacity. The formation of the atheroma plaques is essentially caused by the accumulation of lipid, inflammatory cells and fibrotic elements in the blood vessels causing their obstruction. This process is called atherogenesis and it is the number one cause of CVDs (12).

\footnotetext{
Corresponding Author: Ana Rita Castro, Fernando Pessoa Energy, Environment and Health Research Unit/Biomedical Research Center (FP-ENAS/CEBIMED), Faculty of Health Sciences, Fernando Pessoa University, Porto, Portugal, Email: ritac@ufp.edu.pt
} 
The atherosclerosis process comprises several stages that start with aggression of the endothelium. Oxygen free-radicals present in the blood and increased by tobacco, diabetes mellitus and genetic mutations, oxidize the circulating Low-Density Lipoprotein (LDL), which passes through the weakened endothelium. This lesion will then promote the recruitment of immune cells like monocytes to the site. These monocytes will penetrate the endothelial membrane and transform in macrophages that will opsonize the modified lipoproteins forming the so-called "foam" cells. These will produce more pro-inflammatory cytokines that will intensify the inflammatory process (13).

Afterwards, smooth muscle cells will move to the site forming a more rigid plaque. At this point two types of atheroma plaques can be differentiated: stable and vulnerable. The stable plaques present a dense fibrotic capsule and a minor lipid and inflammatory content. The vulnerable plaques present a thin fibrotic capsule and a high lipid and inflammatory content. Thus, they present a higher probability of rupture resulting in the content release to the blood flow, creating blood clots $(14,15)$.

Concerning the main locations of the atheroma plaques, it is important to emphasize that the location and progression of the atherosclerotic plaque depend on the called "Shear stress", meaning the forces of arterial shearing, created by the blood flow over the surface of the endothelium (16) whenever the shearing tension flow exists. A rapid flow reflects high shearing tension, favouring Nitric Oxide (NO) generation, maintaining the integrity of the vessel. Thus a turbulent flow causes endothelium cells dysfunction causing the start and progression of the atheroma. For that reason, regions of bifurcation are very important in the location of the atheroma plaques namely the coronary, carotid and iliac $(17,18)$.
In the genesis of this atherosclerotic process, the most significant inflammation markers are the cytokines IL-1, IL-6, TNF- $\alpha$ and CRP (19). IL-1 and IL- 6 are cytokines produced by the liver and macrophages play an active role in the development of the inflammatory reaction. TNF- $\alpha$, also a cytokine, interacts with the receptors of the endothelial cells increasing vascular permeability. Adhesion molecules like selectins and cellular adhesion molecules (CAMs), metalloproteinase 3 (MMP- 3) and Reactive Oxygen Species (ROS) can also be used as inflammatory markers of CVDs (20). CRP production is stimulated by IL-6 and both plasma concentrations rise in the inflammatory process $(21,22)$. Although IL-6 initially promotes the inflammatory reaction, it also contributes to its resolution and tissue repair initiation with both pro and anti-inflammatory effects (23). In contrast, in vivo studies indicate that CRP is weakly anti-inflammatory (24) associated to a higher risk of CVD (Figure 1). CRP also acts in the development of the atherosclerotic plaque by activating the complement system via C1q. This last one consists of a complex cascade of proteins that integrate the innate immune system participating in opsonisation, leucocyte chemoattraction, lysis and cellular activation. However, CRP activation can be exacerbated causing the complement system to act favouring the inflammatory process (25).

In addition, CRP also plays a role in the destabilization of the fibrotic layer of the atheroma, mainly by stimulating MMP-1 production by macrophages. This MMP-1 and other proteinases will later degrade the atheroma matrix and its collagen coating. The destabilization also occurs due to the decreasing of the fibrinolytic process and the increase in the synthesis of the Plasminogen Activator Inhibitor (PAI-1) also due to CRP (26).

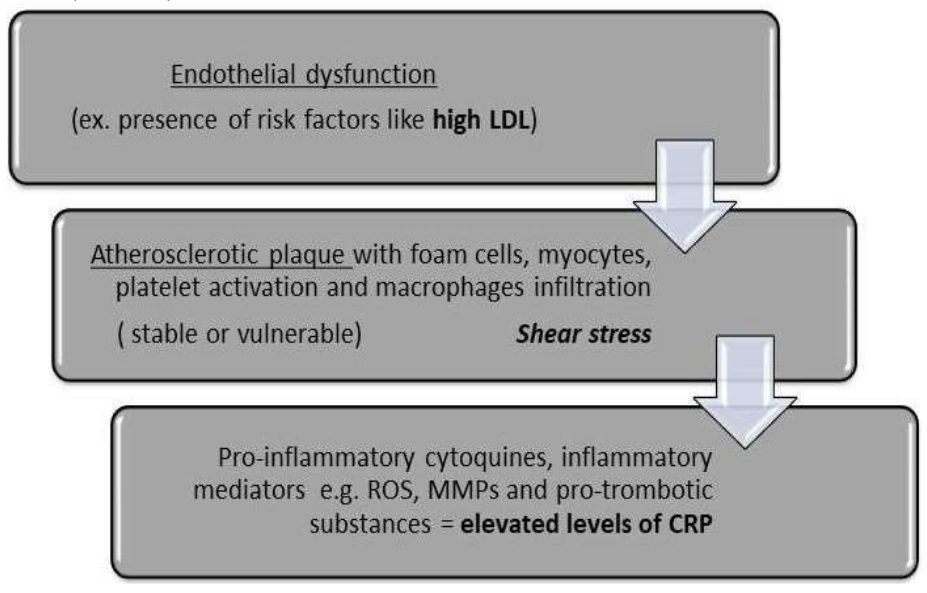

Figure 1. Atherosclerotic process and CRP 
The monitoring of known atherosclerotic risk factors can prevent most of CVDs. Major risk factors include age, gender, genetics, cultural habits, diabetes mellitus, smoking, obesity, diet and a sedentary life style (27).

The aging process potentiates the development of cardiovascular complications through accumulation of several pathologies, like hypertension and hypercholesterolemia (28). Arterial hypertension causes the decrease of the resistance of the blood vessels due to the abnormal increase in the arterial pressure. Thus, endothelium damage occurs easily contributing to the inflammatory process (29). Hypercholesterolemia, when associated to the ingestion of a rich diet in saturated fats or associated to a gene mutation in the receptor of LDL, also increases the risk of atherosclerosis and CVD. There is an increase of this lipoprotein in blood which also increases the probability of arterial deposition (30). Men present a higher probability of developing atherosclerosis and CVDs in comparison to women in premenopause in the absence of other risk factors. In this period women have an increase hormonal protection due to oestrogen production which benefits the endothelium not only by stimulating $\mathrm{NO}$, an endothelial protector, but also for its antioxidant effects. With the onset of menopause, the risk of CVD induced atherosclerosis increases progressively (31). Also, compared to men, women have more adipocytes thereby increasing the cardiovascular risk in the absence of hormonal protection (32). The genetic heritage also reflects the individual susceptibility to develop a certain disease (33) and to respond differently to a certain pharmacologic treatment $(34,35)$. Additionally, cultural and socio-economic differences in the access to primary health care may also constitute a risk factor for the atherosclerotic process.

Hyperglycaemia associated with diabetes mellitus causes the production of free oxygen radicals (process that leads to lipid peroxidation and later to the inflammation process) which also causes tissue damage of the endothelium. Insulin treatment stimulates the NO production but as the disadvantage of also stimulating the production of endothelin-1 (ET-1), that as a vasoconstrictor effect (36). Smoking can lead to an increase of free oxygen radicals that are able to LDL oxidation; also toxins, like nicotine and carbon monoxide can cause lesions in the endothelium as well as inflammation (37). A sedentary lifestyle, obesity and diet are associated to fat accumulation in the arterial membranes and the lack of physical exercise can also potentiate the organism atrophy (36).

\section{C-REACTIVE PROTEIN (CRP)}

CRP was discovered in 1930 (38) and was named after the C- Polysaccharides Pneumococos which caused a reaction in the acute phase of the Pneumococci's pneumonia. This protein belongs to the family of pentraxins (pentameric proteins) with $23 \mathrm{KDa}$. Each subunit has a binding place to phosphatidylcholine and, on the other hand, a binding place for $\mathrm{C} 1 \mathrm{q}$ of the complement system (39).

CRP is a protein produced mainly by the liver in response to several inflammatory cytoquines like IL-1 and IL-6, when there is infection or tissue damage. Locally CRP is secreted by endothelial cells, atheroma plaque, muscle cells of the arterial coronary wall and adipocytes (40). Clinically it is an important inflammatory biomarker because its levels are elevated in patients with coronary disease, mainly those with high cholesterol. Since its serum concentration is not affected by diet or circadian variations, its production is not affected by diseases except those of the liver $(41,42)$.

Concerning the dynamic of CRP, its production starts 4 to 6 hours after a stimulus and doubles each 8 hours, reaching a peak 2 days after the stimulus. It has a semi-life of 19 hours, and it can be days until it returns to basal levels (43). In 1996 (44) showed the prognostic value of increased CRP serum levels in patients with acute myocardial infarction. As mentioned before, CRP serum levels alterations can be measured by hsCRP (45).

\section{HIGH SENSITIVITY CRP CONCENTRATION IN THE DETECTION OF CARDIOVASCULAR DISEASES}

Some authors have referred to hsCRP as a nontraditional CVD risk marker due to its action in the atherosclerosis process (46). hsCRP is positively correlated to the risk of cardiovascular events, hence it can be used as a diagnostic tool (Table 1) $(45,47)$.

A limitation to the use of hsCRP as an inflammatory biomarker is the fact that it is only produced by hepatocytes 4 to 6 hours after stimulus which make CVD quick detection difficult. Another limitation is that CRP takes several days to return to basal levels. Thus, it will not be an accurate biomarker of treatment evolution in the initial phase of recovery after drug treatment (48).

The American Heart Association recommends dismissing hsCRP levels above $10 \mathrm{mg} / \mathrm{L}$ as predictors of CVD risk. A different aetiology, like infections, causing high levels of hsCRP should be considered. Also, new measurements of hsCRP should be performed after

2 weeks to validate/confirm the results (49). 
As an example of alternative aetiology, postmenopausal women taking oestrogen containing oral hormone replacement therapy can have increased hsCRP levels (50). High hsCRP concentrations may also reflect metabolic disorders, including insulin resistance and adiposity $(31,51)$.

Since 2003 the American Heart Association has referred the use of hsCRP as a part of a global assessment of cardiovascular risk (52). After some evolution in the concepts the last report in 2010 by the American College of Cardiology Foundation recommends that the assessment of CRP levels is reasonable for patients at intermediate risk (53). Intermediate risk was previously defined as the predicted risk of a cardiovascular event over 10 consecutive years of $10 \%-20 \%$ (54).

Piccardi and colleagues (55) found a clear association between high hsCRP and cardio embolic stroke. Also high hsCRP is associated with a bad prognosis for patients with hypertrophic cardiomyopathy (56) and ischemic stroke (57).

Increased hsCRP is also a reliable predictor of microvascular dysfunction (MVD).MVD is associated with myocardial injury, supporting the central role of inflammation in the pathophysiology of coronary artery disease (58) (Figure 2).

High hsCRP levels were also correlated with recurrent CVD in patients with type 2 diabetes (56), especially those with poor glycaemic control and known cardiovascular disease (59).

Several drugs can modulate hsCRP and are currently used for primary prevention of CVD, like rosuvastatin and aspirin. In 2008 a randomized, double-blind study (Jupiter) in more than 17000 people, belonging to 26 countries, tested the use of therapy with rosuvastatin in the decrease of hsCRP. It reduced the incidence of cardiovascular events (60), encouraging the use of statins as primary prevention in CVD (61).

An alternative to statin therapy is the use of a monoclonal antibody - Canakinumab - that targets Interleukin-1 $\beta$ reducing the inflammation and hsCRP in patients with low and stable LDL. The use of this anti-inflammatory therapy also resulted efficiently in the decrease of the rate of recurrent cardiovascular events (62). This antibody was formerly used in the CANTOS study Canakinumab Anti-inflammatory thrombosis Outcomes Study (63).

Table 1. Co relation of CVD risk and hsCRP seric concentrations

\begin{tabular}{cc}
\hline Risk Classification & hsCRP (mg/L) concentration \\
\hline & \\
Low risk & $<1$ \\
Medium Risk & $1-3$ \\
High Risk & $>3$ \\
\hline
\end{tabular}

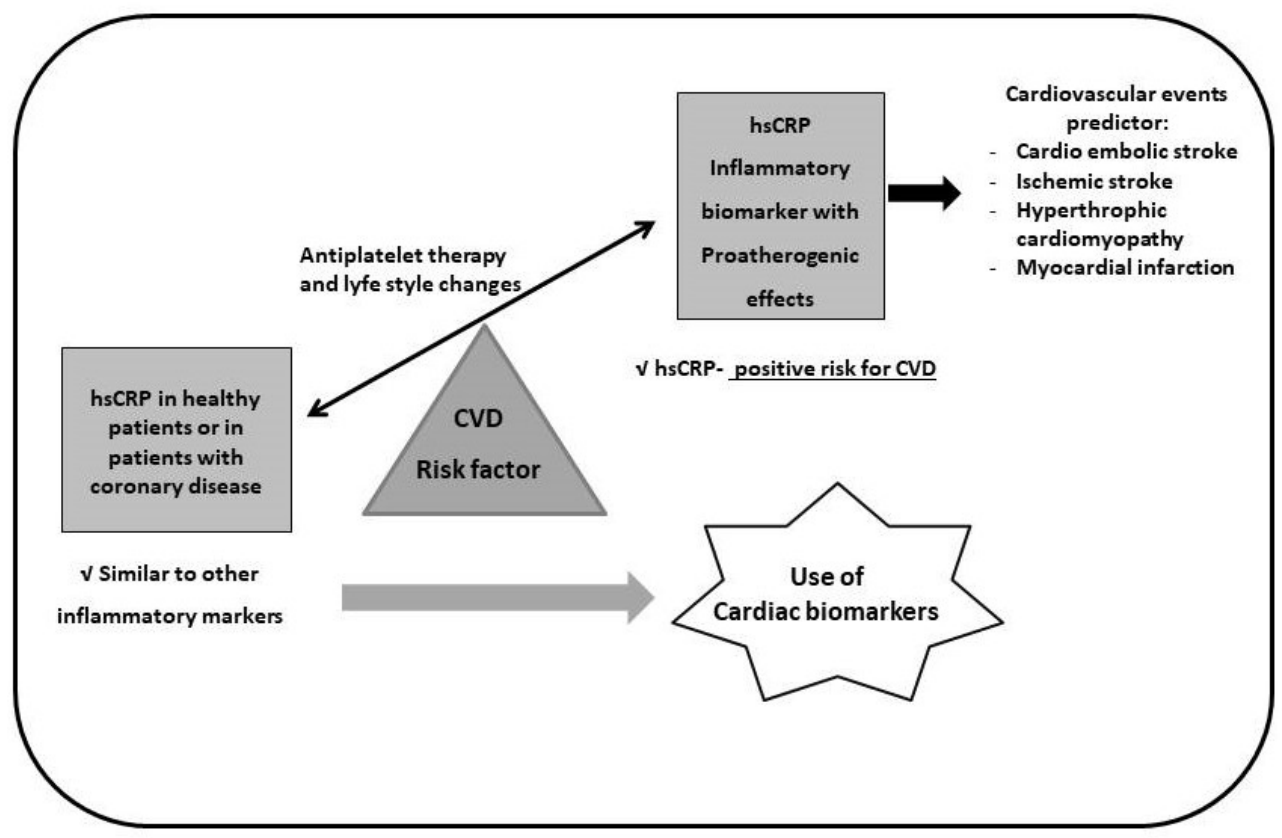

Figure 2. hsCRP and CVD risk 
The use of Acetylsalicylic Acid (AAS), more specifically Aspirin GR $100 \mathrm{mg}$, is also considered a preventive drug for cardiovascular events, reducing the levels of hsCRP (64). Besides pharmacological therapy, it is important to decrease the risk factors/hsCRP concentrations, adopting a healthier life style including low calorie ingestion and low salt diet, physical exercise and smoke cessation (65).

\section{CONCLUSION}

The most common CVDs present the same physiopathologic symptoms as atherosclerosis. Although CRP is an acute phase protein produced in the beginning of the inflammatory process, in high concentration it may cause progression and aggravation of the atherosclerosis. Besides acting as an opsonin, it causes the reduction of NO released which is the main key in endothelial dysfunction. It induces monocyte migration across the endothelium and the expression of adhesion molecules like PAI-1 causing more damage to the atheroma plaque. It also increases the uptake of LDL by macrophages. Thus, in the process of inflammatory response CRP is considered both a biomarker and a risk factor for CVDs. As referred before, it slowly returns to basal levels making it a less accurate biomarker in treatment evolution. Thus, there is still a lack of consensus in the use of hsCRP in the clinical practice.

Recently several authors have claimed that very high hsCRP concentrations $(>10 \mathrm{mg} / \mathrm{L})$ can be used as a marker to identify patients at risk of cardiovascular events like acute myocardial infarction, stroke, cardio embolic or ischemic, and hypertrophic cardiomyopathy. Furthermore, very high hsCRP levels are studied in patients with type 2 diabetes and poor glycaemic control in connection with CVD.

In addition, high levels of hsCRP can be related to infection or inflammation of a different aetiology pointing to the non-specificity of this biomarker. The concerns that hsCRP measurement is not specific for vascular disease are associated with the studies that show the same high hsCRP levels in patients with other metabolic disorders. hsCRP levels might be useful in the stratification of patients at intermediate risk for a cardiovascular event. Regarding this latest research it could be useful to establish a high concentration limit of hsCRP.

Despite these studies, the cost effectiveness of hsCRP screening is still an area of controversy. For some cardiologists, the primary interventions for patients with high hsCRP are lifestyle alterations together with antiplatelet therapy.
Although there are some limitations to the use of hsCRP, it has recently been found that high levels of hsCRP correlate with a positive risk for CVD development, especially in coronary diseases. In the future this inflammatory biomarker/CVD risk factor may also be useful in the detection of other diseases besides cardiovascular ones caused by atherosclerosis.

\section{REFERENCES}

1. World Health Organization. Global Atlas on cardiovascular disease prevention and control. Geneva, 2011.

2. Direção-Geral da Saúde. Portugal: Doenças Cérebro-Cardiovasculares em números-2015. 2015, Lisboa, ISSN: 2183-0681.

3. Libby P, Ridker P, Hansson GK. Progress and challenges in translating the biology of atherosclerosis. Nature, 2011; 473: 317-325. doi: 10.1038/nature 10146

4. Kulmatycki KM, Jamali F. Therapeutic relevance of altered cytokine expression. Cytokine, 2001; 7;14: 1-10. doi: $10.1006 /$ cyto.2000.0827

5. Kulmatycki KM, Jamali F. Drug disease interactions: role of inflammatory mediators in disease and variability in drug response. J Pharm Pharm Sci., 2005; 16: 602-625. doi:10.1006/cyto.2000.0827

6. Bursi B, Weston SA, Killian JM, Gabriel SE, Jacobsen SJ, Roger VL. Reactive Protein and Heart Failure after Myocardial Infarction in the Community. The American Journal of Medicine, 2007; 120: 616-622. doi.org/10.1016/j.amjmed.2006.07.039

7. Papanicolaou DA, Wilder RL, Manolagas SC, Chrousos GP. The pathophysiologic roles of interleukin-6 in human disease. Ann. Intern. Med., 1998; 128: 127-137.

8. Howren MB, Lamkin DM, Suls J. Associations of depression with C-reactive protein, IL-1, and IL-6: a meta-analysis. Psychosom. Med., 2009; 71: 171186.

9. Clyne B, Olshaker JS. The C-reactive protein. J Emerg Med. 1999, 17, 1019-1025, doi: 10.1161/ATVBAHA

10. Kaptoge,S, Di Angelantonio E, Pennells L, et al., C-reactive protein, fibrinogen, and cardiovascular disease prediction. N Engl J Med. 2012; 4, 367: 1310-1320. doi: 10.1056/NEJMoa1107477.

11. Ridker PM. Clinical application of C-reactive protein for cardiovascular disease detection and prevention. Circulation 2003; 107: 363-9 doi.org/10.1161/01.CIR.0000053730.47739.3C

12. Gimbrone MA Jr, Topper JN, Nagel T, Anderson KR, Garcia-Cardena G. Endothelial dysfunction, hemodynamic forces, and atherogenesis. Ann N Y Acad Sci. 2000; 902: 230-239

13. Bobryshev YV. Monocyte recruitment and foam cell formation in atherosclerosis. Micron 2006; 37 : 208-222 
14. Librandi AP, Pandochi AI. O envolvimento do sistema de complemento nos processos de aterogénese. Medicina, 2008; 41: 312-326.

15. Singh R, Mengi S, Xu Y, Arneja A, Dhalla N. Pathogenesis of atherosclerosis: A multifactorial process. Experimental \& Clinical Cardiology, 2002; 7: 40-53.

16. Bonow RE, Mann DL, Zipes DP, Libby $P$. Braunwald - Tratado de doenças cardiovasculares. $9^{a}$ Ed.; Saunders Elsevier, 2013, S. Paulo, ISBN 978-1-4377-2708-1.

17. Nakazawa G. Pathological Findings at Bifurcation Lesions - The Impact of Flow Distribution on Atherosclerosis and Arterial Healing After Stent Implantation. Journal of the American College of Cardiology. 2010; 55: 1679-1687

18. Dhawan SS, Nanjundappa R, Branch JR, Taylor WR. Quyyumi AA, Jo H, McDaniel MC, Suo J, Giddens D, Samady H. Shear stress and plaque development. Expert Rev Cardiovasc Ther 2010; 8: 545-56, doi: 10.1586/erc.10.28.

19. Lind L. Review Circulating markers of inflammation and atherosclerosis. Atherosclerosis 2003; 169: 203-214. doi:10.1016/S00219150(03)00012-1.

20. Ridker PM, Rifai N, Pfeffer M, Sacks F, Lepage S, Braunwald E. Elevation of tumor necrosis factor- $\alpha$ and increased risk of recurrent coronary events after myocardial infarction. Circulation. 2000; 101(18):2149-2153. 10.1161/01.CIR.101.18.2149

21. Pai JK, Pischon T, Ma J, Manson JE, Hankinson SE, Joshipura K, et al. Inflammatory markers and the risk of coronary heart disease in men and women. N Engl J Med., 2004; 351(25):2599-2610. doi: 10.1056/NEJMoa040967

22. Ridker PM, Rifai N, Stampfer MJ, Hennekens CH. Plasma concentration of Interleukin- 6 and the risk of future myocardial infarction among apparently healthy men. Circulation. 2000; 101(15):17671772. doi: 10.1161/01.CIR.101.15.1767

23. Fuster JJ, Walsh K. The Good, the Bad, and the Ugly of interleukin-6 signaling The EMBO journal, 2014; 33: 1425-1427, doi: 10.15252/embj.201488856

24. Eisenhardt SU, Thiele JR, Bannasch H, Stark GB. Karlheinz P. C-reactive protein: How conformational changes influence inflammatory properties. Cell cycle, 2009; 8, 23: 3885-3892, doi: 10.4161/cc.8.23.10068

25. Yasojima K, Schwab C, McGeer EG, McGeer PL. Generation of C-reactive protein and complement components in atherosclerotic plaques. Am J Pathol., 2001; 158: 1039-1051.

26. Teixeira BC, Lopes AL, Macedo R, Correa CS. Marcadores inflamatórios, função endotelial e riscos cardiovasculares. Jornal vascular brasileiro, 2014; 13: 108-115.

27. Roberts WC. Atherosclerotic risk factors - are there ten, or is there only one? 1992. 97: S5-S9. doi: 10.1016/0021-9150(92)90158-D

28. Safar ME, Thomas F, Blacher J, Nzietchueng R, Bureau .JM, Pannier B, Benetos A. Metabolic syndrome and age-related progression of aortic stiffness. J. Am. Coll Cardiol, 2006; 47: 72-75

29. Brandes RP. Endothelial Dysfunction and Hypertension. Hypertension. 2014; 64: 924-928

30. Chang CL, Seo T, Matsuzaki M, Worgall TS, Deckelbaum RJ. n-3 fatty acids reduce arterial LDL-cholesterol delivery and arterial lipoprotein lipase levels and lipase distribution. Arterioscler Thromb Vasc Biol. 2009; 29: 555-561

31. Guetta V, Cannon R. Cardiovascular effects of estrogen and lipid-lowering therapies in postmenopausal women. Circulation, 1996; 93: 1928-1937

32. Geer EB, Shen W. Gender differences in insulin resistance, body composition, and energy balance. Gend. Med. 2009; 6 (Suppl 1): 60-75

33. Auer PL, Stitziel NO. Genetic association studies in cardiovascular diseases: Do we have enough power? Trends Cardiovasc Med. 2017; 27: 397-404

34. Ritchey M, Chang A, Powers C, Loustalot F, Schieb L, Ketcham MM, Durthaler J, Hong Y. Vital Signs: Disparities in Antihypertensive Medication Nonadherence Among Medicare Part D Beneficiaries - United States, 2014. MMWR Morb Mortal Wkly Rep. 2016; 65: 967-76

35. Hage, FG, Szalai AJ. C-reactive protein gene polymorphisms, C-reactive protein blood levels, and cardiovascular disease risk. J Am Coll Cardiol. 2007; 50: 1115-22. Epub 2007 Sep 4.

36. Siqueira A, Pititto B, Ferreira S. Doença cardiovascular no Diabetes Mellitus: Análise dos fatores de risco clássicos e não clássicos. Arquivo brasileiro e endocrinologia e metabologia, 2007; 51: 257-267.

37. RM. Cigarette smoking, endothelial injury and cardiovascular disease Int J Exp Pathol., 2000; 81: 219-230.

38. Silva SH, Moresco RN. Biomarcadores cardíacos na avaliação da síndrome coronariana aguda. Scientia Medica (Porto Alegre), 2011, 21, 132-142

39. DuClos TW, Mold C. Pentraxins (CRP, SAP) in the process of complement activation and clearance of apoptotic bodies through Fc $\gamma$ receptors Curr Opin Organ Transplant 2011; 16: 15-20

40. Pitthan E, Martins OMO, Barbisan JN. Novos biomarcadores inflamatórios e de disfunção endotelial: predição de risco cardiovascular. Revista da AMRIGS, 2014; 58: 69-77.

41. Rader DJ. Inflammatory markers of coronary risk. N Engl J Med., 2000, 343, 1179-82.

42. Ridker PM. High sensitivity C-reactive protein Circulation, 2001; 103: 1813-1818.

43. Aguiar FB, Júnior MF, Sales MM, Cruz-Neto LM, Fonseca LAM, Sumita NM, Duarte NJ, Lichtenstein A, Duarte AJS. Proteína C reativa: aplicações clínicas e propostas para utilização racional. Rev Associação Médica Brasileira 2013; 59: 85-92.

44. Pietilä KO, Harmoinen AP, Jokiniitty J, Pasternack AI. Serum C-reactive protein concentration in acute myocardial infarction and its relationship to mortality during 24 months of follow-up in patients 
under thrombolytic treatment. Eur Heart J.1996; 17(9):1345-9.

45. Roberts WL. CDC/AHA Workshop on Markers of Inflammation and Cardiovascular Disease: Application to Clinical and Public Health Practice: laboratory tests available to assess inflammation-performance and standardization: a background paper. Circulation, 2004; 110:e572-6.

46. Whayne TF. Non-traditional cardiovascular risk markers in the era of established major risk factors and multiple guidelines. Curr Vasc Pharmacol 2018; 16, doi: 10.2174/1570161116666180123112956.

47. Ridker PM, Cook N. Clinical usefulness of very high and very low levels of C-reactive protein across the full range of Framingham Risk Scores Circulation, 2004; 109:1955-1959 DOI: 10.1161/01.CIR.0000125690.80303.A8

48. Ridker PM. A Test in Context: High-Sensitivity CReactive Protein. J Am Coll Cardiol., 2016; 67: 712-723.

49. Pearson TA, Mensah GA, Alexander RW, Anderson JL, Cannon RO, Criqui M, Fadl YY, Fortmann SP, Hong Y, Myers G.L.; Rifai, N.; Smith, S.C.; Taubert, K.; Tracy, R.P.; Markers of inflammation and cardiovascular disease: application to clinical and public health practice: A statement for healthcare professionals from the Centers for Disease Control and Prevention and the American Heart Association Circulation, 2003; 107: 499-511.

50. Ebong IA, Schreiner P, Lewis CE, Appiah D, Ghelani A, Wellons M. The association between high-sensitivity C-reactive protein and hypertension in women of the CARDIA study. Menopause. 2016; 23: 662-8. doi: 10.1097/GME.0000000000000609.

51. Guldiken S, Demir M, Arikan E, Turgut B, Azcan S, Gerenli M, Tugrul A. The levels of circulating markers of atherosclerosis and inflammation in subjects with different degrees of body mass index: Soluble CD40 ligand and high-sensitivity Creactive protein. Thromb Res. 2007; 19:79-84. doi: 10.1016/j.thromres.2005.12.019

52. Pearson TA, Mensah GA, Alexander RW, Anderson JL, Cannon RO, Criqui M, Fadl YY, Fortmann SP, Hong Y, Myers GL, Rifai N, Smith SC, Taubert K, Tracy RP. Markers of inflammation and cardiovascular disease: application to clinical and public health practice: A statement for healthcare professionals from the Centers for Disease Control and Prevention and the American Heart Association, Circulation, 2003; 107: 499511.

53. Greenland P, Alpert JS, Beller GA, et al. 2010 ACCF/AHA guideline for assessment of cardiovascular risk in asymptomatic adults: a report of the American College of Cardiology Foundation/American Heart Association Task Force on Practice Guidelines. J. Am Coll Cardiol. 2010; 56: 25 :e50-e103.

54. Genest J, McPherson R, Frohlich J, et al. 2009 Canadian Cardiovascular Society/Canadian guidelines for the diagnosis and treatment of dyslipidemia and prevention of cardiovascular disease in the adult - 2009 recommendations. Can J Cardiol. 2009; 25: 567-79.

55. Piccardi B, Giralt D, Bustamante A, Llombart V, García-Berrocoso T, Inzitari D, Montaner J. Blood markers of inflammation and endothelial dysfunction in cardioembolic stroke: systematic review and meta-analysis Biomarkers. 2017; 22: 200-209.

56. Zhu L, Zou Y, Wang Y, Luo X, Sun K, Wang H, Jia L, Liu Y, Zou J, Yuan Z, Hui R, Kang L, Song L, Wang J. Prognostic Significance of Plasma High-Sensitivity C-Reactive Protein in Patients With Hypertrophic Cardiomyopathy. J Am Heart Assoc., 2017; 6, 2: 1-7 doi: 10.1161/JAHA.116.004529.

57. Itrat A, Griffith SD, Alam S, Thompson N, Katzan IL. The role of very high high-sensitivity C-reactive protein levels on mortality after stroke. J Neurol Sci.2017; 372: 1-5, doi: 10.1016/j.jns.2016.11.019

58. Piccardi B, Giralt D, Bustamante A, Llombart V, García-Berrocoso T, Inzitari D, Montaner J. Blood markers of inflammation and endothelial dysfunction in cardioembolic stroke: systematic review and meta-analysis Biomarkers. 2017; 22: 200-209.

59. Itrat A, Griffith SD, Alam S, Thompson N, Katzan IL. The role of very high high-sensitivity C-reactive protein levels on mortality after stroke. J Neurol Sci.2017, 372: 1-5, doi: 10.1016/j.jns.2016.11.019

60. Ridker PM, Danielson E, Fonseca FAH, Genest J, Gottto AM, Kastelein JJP, Koenig W, Libby P, Lorenzatti AJ, MacFadyen JG, Nordestgaard BG, Shepherd J, Willerson JT, Glynn RJ. for the JUPITER Study Group. Rosuvastatin to prevent vascular events in men and women with elevated Creactive protein. N Engl J Med. 2008; 359: 2195 2207.

61. Verma A, Lavie CJ, Milani RV. C-Reactive Protein: How Has JUPITER Impacted Clinical Practice? Ochsner J., 2009; 9: 204-210.

62. Ridker PM, Everett BM, Thuren T, MacFadyem JG, Chang WH, Ballantyne C, Fonseca F, Nicolau J, Koenig W, Anker SD, Kastelein JJP, Cornel JH, Pais P, Pella D, Genest J, Cifkova J, Lorenzati A, Forster T, Kobalava Z, Vida-Simiti L. for the CANTOS Trial Group. Antiinflammatory Therapy with Canakinumab for Atherosclerotic Disease. New Eng J. Medicine, 2017; 377: 1119-1131.

63. Ridker PM, MacFadyen JG, Everett BM, Libby P, Thuren T, Glynn RJ. On behalf of the CANTOS Trial Group* Relationship of C-reactive protein reduction to cardiovascular event reduction following treatment with canakinumab: a secondary analysis from the CANTOS randomised controlled trial. The lancet. 2018; 391 (10118): 319-328. doi: 10.1016/S0140-6736(17)32814-3

64. Vaucher J, Marques-Vidal P, G, Waeber G, Vollenweider P. Cytokines and hs-CRP levels in individuals treated with low-dose aspirin for cardiovascular prevention: A population-based 
study (CoLaus Study) Citokine, 2014; 66: 2, 95100. doi.org/10.1016/j.cyto.2014.01.003

65. Soltani S, Chitsazi MJ, Salehi-Abargouei A. The effect of dietary approaches to stop hypertension (DASH) on serum inflammatory markers: A systematic review and meta-analysis of randomized trials. Clin Nutr., 2018; 37: 542-550. 